\title{
Assimilating NOAA SST data into the BSH operational circulation model for the North and Baltic Seas: Inference about the data
}

\author{
Svetlana N. Losa ${ }^{a, *}$, Sergey Danilov ${ }^{\text {a }}$, Jens Schröter ${ }^{a}$, Lars Nerger ${ }^{\text {a }}$, Silvia \\ Maßmann ${ }^{\mathrm{b}}$, Frank Janssen ${ }^{\mathrm{b}}$ \\ ${ }^{a}$ Alfred Wegener Institute for Polar and Marine Research, Bremerhaven, Germany \\ ${ }^{b}$ German Maritime and Hydrographic Agency (BSH),Hamburg, Germany
}

\begin{abstract}
The operational ocean prediction model for the North and Baltic Seas of the German Maritime and Hydrographic Agency (BSH) is augmented with a multivariate data assimilation (DA) system. We report on the implementation and performance of the scheme which is based on ensemble forecasting. Here we apply the localized Singular Evolutive Interpolated Kalman (SEIK) filter for assimilating the NOAA AVHRR-derived sea surface temperature (SST) data.

Results are presented for two periods: October 2007 is used for calibration and March 2011 for the analysis of the performance in a pre-operational phase. The major forecast improvement is found to be a reduction in the local temperature bias. As compared with the regular BSH forecast without assimilation, the root mean square difference between the predicted SST and satellite observations is reduced on average from $0.87^{\circ} \mathrm{C}$ to $0.53^{\circ} \mathrm{C}$ for March
\end{abstract}

\footnotetext{
${ }^{*}$ Corresponding author

Email address: Svetlana.Losa@awi.de (Svetlana N. Losa)
} 
2011. The quality of the predicted fields that were not assimilated (velocities, sea level and salinity) is preserved as is confirmed by independent in situ data. The results have required adjustment of the conditional data error statistics.

The experiments conducted with different timing and frequency of data assimilation and variable forecasting periods show that the DA system corrects systematic model uncertainties and, due to memory to the corrections, improves prediction over periods of up to 5 days. The results also explicitly illustrate a lower quality of the AVHRR daytime product and reveal low informative influence of the data on the forecasting system when daytime SSTs are assimilated additionally to midnight observations.

Keywords: data assimilation, ensemble Kalman filtering, operational forecasting

\section{Introduction}

Over the last two decades many Earth's system observing programs have been established in order to monitor, investigate and understand the changes in Earth's climate and the influence of human activities on the environment. A number of satellite missions have been launched to observe the state of the Earth's subsystems, including the global ocean. Additional information about the ocean state is provided by in situ data, e.g. from deployed floats. A combination of the data with numerical modeling via assimilation proves to be a powerful tool either for just interpolation and (re)analysis of the sometimes still sparse data, or for the design of monitoring strategies, as well as for long- and short-term system state forecasts.

A number of operational ocean forecasting systems with data assimilation 
(DA) demonstrated remarkable progress during the past 10 years (e.g. Brusdal et al., 2003; Bertino and Lisæter, 2008; Brasseur et al., 2005; Cummings et al., 2009; Storkey et al., 2010; Kurapov et al., 2011; Stanev et al., 2011). In vein with this general line, a new data assimilative forecasting system has been recently developed to operate for the North and Baltic Seas. Since 1 January 1999, the German Maritime and Hydrographic Agency (BSH) has been operationally running a circulation model for the North and Baltic Seas coupled with an ice model. On a daily basis, up to 72 hour forecasts of sea surface elevation, currents, water temperature and salinity, as well as forecast of sea ice concentration and thickness are produced. Within the project DeMarine-Environment - as a part of the GMES initiative (Ryder, 2007) - the operational system of the BSH has been extended by including a data assimilation component, in particular, for assimilating NOAA's (National Oceanic and Atmospheric Administration) satellite sea surface temperature (SST) data into the BSH circulation model. Previously, She et al. (2007) and Larsen et al. (2007) noted that the satellite data, due to their temporal and spatial coverage, are better suited for the North and Baltic Seas SST reconstruction (Høyer and She, 2007) than in situ measurements.

The aim of this paper is to investigate whether and under which optimal setting the satellite sea surface temperature data assimilation gives one an opportunity to improve the forecasting service provided by the BSH. Improved SST fields on their own are required for monitoring climate change and for the specification of oceanic boundary conditions for atmospheric models and to provide initial conditions for ocean/sea circulation models. Moreover, proper SST forecasting skills are of importance when predicting sea-ice. Pri- 
mary productivity and water quality - for instance, harmful algal bloom and oxygen hypoxia events - are also influenced by temperature either directly, through the dependence of physiology and gas exchange processes on it, or indirectly via changes in mixing conditions and stratification in the upper mixed layer, in which phytoplankton grows. It is worth noting, however, that, optimizing the data assimilation system, one has to consider not only the system's forecasting skills with respect to SST, but also the performance in simulating sea surface elevation, current velocities and salinity, which are vital for other applications.

The degree of the forecast quality improvement due to data assimilation crucially depends on our prior assumptions on model and data error statistics and on how the statistics evolve in space and time. The latter is, to a large extent, determined by data assimilation algorithms. In this study, the Singular Evolutive Interpolated Kalman (SEIK) filter (Pham et al., 1998; Pham, 2001 ) is used. This ensemble-based method is suboptimal as many practical Kalman-type filters. It requires a substantial calibration effort given a particular dynamical system and data (for more details see the next section). Moreover, as a rule, we know little about model error statistics, and the prior information on data errors is also missing in our application. These circumstances make the problem of optimizing the BSH operational data assimilative system rather challenging. They also change the context of statistical terms with respect to the system error statistics. In absence of precise information about the reality, the model and data errors, considered relative to this reality, are linked to each other. In this work, we focus on assumptions about data errors and discuss SST data assimilation results obtained 
with several different (with respect to timing, period, frequency) forecasting schemes, based on the forcing and data collected for October 2007. We propose that data assimilation may teach us about error statistics and eventually allows us a posteriori estimate the model uncertainties and draw conclusions about data. Let us emphasize, however, that we do not intend to provide quantitative estimates of the data errors, but rather to evaluate the relative quality of this information source about the reality. Thus, in this paper, we demonstrate that:

1. By carefully selecting the radius of the data influence in a local SEIK filter implementation and functions approximating the data error correlations, the forecast skills of the BSH model can be markedly improved.

2. The calibrated data assimilation system is capable of correcting the systematic model uncertainties and keeps the corrections and model trajectories in the right direction over more than 100 hours. This opens perspectives for long-term forecasting over several days and is also important in the presence of many data gaps at different locations in the North and Baltic Seas caused by clouds.

3. It is possible to infer on data quality via assimilation.

The next section describes the system including the BSH operational model of the North and Baltic Seas, the data and the implemented data assimilation approach. In section 3 we explain the experiment design. Results of data assimilation system calibration and results of pilot real-time experiments are presented in section 4 . The last section provides a summary and some conclusions. 
There are still some aspects of the system development which are left beyond the scope of the paper but are indeed crucial. Based on system evaluation over a one year period (October 2007 - September 2008), we have found that plausible estimates or hypothesis on model errors and their seasonal variability are necessary for keeping the improvement of sea ice and bottom temperature forecast on a long term. In a separate paper, we discuss the sensitivity of the system performance to the initial model error specification and consider possible evaluation of the plausibility of the filter analysis and error statistics.

\section{Pre-operational System}

\section{BSH operational circulation model}

The operational circulation model of the BSH (BSHcmod, Kleine, 1994; Dick, 1997; Dick et al., 2001) is a three-dimensional hydrostatic primitiveequation circulation model formulated in spherical horizontal and generalised vertical coordinates (Kleine, 2003), with mixing length formulation for horizontal and vertical turbulence.

The model domain extends from $4^{\circ} \mathrm{W}$ to $30,5^{\circ} \mathrm{E}$ and from $48,5^{\circ} \mathrm{N}$ to $60,5^{\circ} \mathrm{N}$ in the North Sea and to $66^{\circ} \mathrm{N}$ in the Baltic Sea. The horizontal grid spacing is $\sim 5 \mathrm{~km}, 5^{\prime}$ in longitude and 3' in latitude. The vertical dimension is discretized into 44 vertical layers, with layer thickness increasing from $\sim 2 \mathrm{~m}$ at the top to $\sim 3 \mathrm{~m}$ close to the bottom. The operational version of BSHcmod uses a two-way nested high resolution $(\sim 900 \mathrm{~m})$ grid, which covers the German Bight and the western Baltic Sea. For this study the model is run without nesting in order to reduce the computational cost. Judging on 
existing dynamics, the exclusion of the high resolution nested grid has minor influence on the results with respect to SST. It may, however, have a strong impact on the Baltic Sea salinity as discussed later.

The northern open boundary in the North Sea is closed with a sponge layer. Within this layer, the temperature and salinity are restored towards monthly mean climatological values. A similar sponge region is included at the entrance to the English Channel. External surges at the open boundaries are provided by a two-dimensional BSH model for the North East Atlantic with coarser resolution of $\sim 10 \mathrm{~km}$. 14 tidal constituents are used to implement tidal forcing, and flooding and drying of tidal flats is applied. Atmospheric forcing at the surface is based on meteorological forecast data - hourly values of air temperature and humidity, air pressure, wind velocity and total cloud cover - provided by German Weather Service (DWD). River runoff is prescribed as freshwater fluxes at the boundaries opened in the regions of main rivers.

To account for ice formation processes at the sea surface, the BSH circulation model is coupled with a sea ice model that describes sea ice thermodynamics and incorporates Hibler-type dynamics (Hibler, 1979).

Operationally, the BSHcmod is integrated once per day over up to 72 hours with the time step of $30 \mathrm{~s}$.

Despite the fact that the BSH coupled sea/ocean circulation-ice model accounts for and describes many physical processes observed in reality, the model is, as any others, just an approximation of the real world. We expect that the quality of hydrographic characteristics forecast provided by the model can still be improved by assimilating observational data. 
Observational Data

The observational data are 12 hourly — centered around 00:00 and 12:00, - composites of SST data measured by the Advanced Very High Resolution Radiometer (AVHRR) aboard polar orbiting NOAA satellites and processed and gridded by the BSH satellite data service. Here, we focus on the data collected over October 2007 (DA tuning period) and over March 2011 (a realtime experiment period). Only the satellite data for these particular periods were taken into account.

\section{Data Assimilation approach}

We use data assimilation to estimate and predict a system state $\mathbf{x}(t)$ given observations and a dynamical model evolving with time $t$ according to

$$
\frac{d \mathbf{x}}{d t}=\mathbf{L}(\mathbf{x}, t)+\mathbf{F}(t)
$$

where $\mathbf{L}$ is the model operator describing internal processes and $\mathbf{F}$ is the external forcing. One has to consider several approximations for this process:

1. The dynamical model is always an approximation to some natural phenomena. It possesses uncertainties in the external forcing $\mathbf{F}$ and initial condition $\mathbf{x}(0)$, and in some internal parameterization. Given these uncertainties it is worth presenting the system forecast as a set of probable predictions $\mathbf{x}(t)$ of state $X_{t}, \mathbf{x}(t) \in X_{t}$. Thus, the forecast can be expressed in terms of probability density function (PDF), $\rho_{t}^{f}(\mathbf{x}(t))$, defined over $X_{t}$,

$$
\rho_{t}^{f}(\mathbf{x}(t))=C \rho^{f}(\mathbf{x}(t) \mid \mathbf{x}(0)) \rho_{0}(\mathbf{x}(0)) .
$$


Here $C$ is the normalization constant, $\rho_{0}$ is the PDF describing uncertainties in the initial condition, and $\rho^{f}(\mathbf{x}(t) \mid \mathbf{x}(0))$ is the conditional PDF evolving in time, in accordance with the so-called Fokker-PlanckKolmogorov (FPK) equation, which corresponds to the stochastic dynamical model

$$
\frac{d \mathbf{x}}{d t}=\mathbf{L}(\mathbf{x}, t)+\mathbf{F}(t)+\varepsilon,
$$

where $\varepsilon$ is a stochastic process with the statistics describing the model errors. The statistics is, indeed, a priori poorly known.

2. The observations are also imperfect and contain some errors. Their probability density function is introduced through the conditional PDF $\rho_{d}(\mathbf{d} \mid \mathbf{x})$ of the data $\mathbf{d}$ to be observed if the true system state is $\mathbf{x}$.

3. The problem of state estimation, i.e. combining the uncertain model and imperfect data, formulated globally over the space of model trajectories $X=\oplus X_{t}$ can be considered as the search for most probable realisations of model trajectories given the data. This reduces to estimating the conditional $\mathrm{PDF} \rho^{a}(\mathbf{x} \mid \mathbf{d})$, with is also called the analysis PDF. It expresses our knowledge about the model state when data are observed and can be found with the Bayesian theorem (van Leeuwen and Evensen, 1996)

$$
\rho^{a}(\mathbf{x} \mid \mathbf{d})=C \rho_{d}(\mathbf{d} \mid \mathbf{x}) \rho(\mathbf{x}) .
$$

With a discrete analogue of system (3), equation (4) gives

$$
\rho(\mathbf{x})=C \rho_{0}(\mathbf{x}(0)) \Pi_{k=1}^{M} \rho^{f}(\mathbf{x}(k \Delta t) \mid \mathbf{x}((k-1) \Delta t)),
$$

where $M$ is the number of time steps of the length $\Delta t$. Solving Eq. (5) requires calculations in the space of dimension $\operatorname{Mdim}\left(X_{t}\right)$. This dimen- 
sion is, however, huge for many oceanographic applications (Brusdal et al., 2003; Penduff et al., 2002; Testut et al., 2003).

To reduce the dimension of control space by factor $M$ one can either neglect the model errors (strong constraint variational techniques) or consider the problem of data assimilation sequentially (statistical methods). With the last approach, we integrate the FPK equation just from initial time till the time the observation becomes available. Then, we use the evolved forecast $\operatorname{PDF}\left(\rho_{t}^{f}\left(\mathbf{x}\left(t_{1}\right)\right)\right.$ as prior when calculating the analysis PDF $\rho_{t}^{a}$

$$
\rho_{t}^{a}\left(\mathbf{x}\left(t_{1}\right) \mid \mathbf{d}_{1}\right)=C \rho_{d}\left(\mathbf{d}_{1} \mid \mathbf{x}\left(t_{1}\right)\right) \rho_{t}^{f}\left(\mathbf{x}\left(t_{1}\right)\right) .
$$

4. Integrating the FPK equation explicitly is only feasible for very small systems. For larger systems the computation of $\rho_{t}^{f}$ has to be approximated. One possibility is to apply the Kalman Filter (see, Ghil and Malonotte-Rizzoli, 1991) or the Extended Kalman filter (Jazwinski, 1970). These filters assume Gaussian statistics and use only the covariance matrix corresponding of the full PDF. They are optimal only for linear systems. Furthermore, applying the Extended Kalman Filter for non-linear systems can be problematic due to a linearisation of FPK equation around the current analysis state (see Evensen, 1994).

No linearization is required if the continuous PDF is approximated with an ensemble of model states. The forecast error statistics, in these socalled Monte Carlo based algorithms, is derived from the "cloud" of ensemble members evolving in accordance to the stochastic dynamical model (3). At the analysis step, given the observations, one can do 
sampling based either on full statistics of the PDF (particle filtering, see e.g., Gordon et al., 1993; Kivman, 2003; van Leeuwen, 2009, 2010) or, under the assumption of Gaussian statistics, just use the forecast error covariance matrix as in the Kalman Filter (Ensemble Kalman filter EnKF by Evensen, 1994).

The convergence rate of the Monte Carlo methods depends on the number $(N)$ and distribution of nodes sampling the space. Increasing $N$ improves the approximation of the PDF.

5. The computational cost of an assimilation method is widely determined by the time to integrate the ensemble of model states. Thus, sampling strategies that allow one to use an ensemble of minimum size are of particular relevance. The singular evolutive interpolated Kalman (SEIK) filter (Pham et al, 1998, Pham, 2001) similarly to the ensemble transform Kalman filter (ETKF by Bishop et al., 2001) can be considered as a variant of the EnKF "using a minimum number of ensemble members" (Pham, 2001). At the analysis step, this, still of Kalman-type, reduced rank square root filter spans the control space based on the empirical orthogonal functions (EOFs) of the ensemble.

6. One more approximation applied in order to reduce the ensemble size is localization (for overview see Janjić et al., 2011), in other words, sampling which is optimal to each particular subspace (fragment of space $X_{t}$ ), rather than to the global space. In practice, localisation algorithms applied in ensemble-based Kalman filters introduce a radius of data influence and a weighting of the observation influence based on an assumed correlation function (Nerger et al., 2006; Hunt et al., 2007; 
Miyoshi and Yamane, 2007). Such an approximation, as a rule, needs calibration of the algorithm with respect to the radius and the function describing the data error correlations.

These considerations show that success of any data assimilation system is based on properly solving the problems of presentation of probable model uncertainties, data error approximation and propagation of these model and data error statistics in time with the used data assimilation algorithm. In this study, we sequentially (3) combine the information about the hydrographic characteristics provided by the BSH circulation model and SST satellite measurements by implementing the ensemble based (4) SEIK filter (5) with second order exact sampling (Pham, 2001) coded within the Parallel Data Assimilation Framework (PDAF, Nerger et al., 2005; Nerger and Hiller, 2012). While using the SEIK filter makes the DA problem tractable with a relative small ensemble, one can reach noticeable improvement in the performance of the data assimilation system by applying SEIK filtering locally (6, LSEIK) as in the study by Nerger et al. (2006), but with different data error correlation functions or, in other words, with different ways of data weighting. Keeping in mind all the aforementioned approximations (1-6) and the fact that, indeed, a priori we know little about the model and data errors $(1,2)$ it is worth emphasizing that in practice, to assimilate the satellite-derived SST data into BSHcmod, we need to calibrate the data assimilation system with respect to assumed initial model error statistics and localization conditions when filtering based on the ensemble of a certain (small) size and with given observational errors. In this paper we address aspects of the DA system optimization concerning the sensitivity of the system performance to 
our assumptions about the data error statistics.

\section{Experiment design}

For validating the developed data assimilative BSH forecasting system and performing required sensitivity experiments, we have been provided with atmospheric and river run-off data as well as with assimilated NOAA SSTs over the period of 1 October 2007 - 30 September 2008. Because of computational cost (1 model day required 1.5 hours of computer time), calibration of the system had been done for the first month of the model integration. As soon as the DA system had been developed (end of 2010) and passed over to the BSH, pre-operational simulations had been started. For this period, the very first real-time data assimilation experiment performed in March 2011 is presented, too. These results are considered as additional validation of the BSH North and Baltic Seas forecasting system augmented with SST data assimilation.

\subsection{Model and data error statistics}

Initial model error covariances

The initial model error covariance matrix, approximating $\rho_{0}$, has been computed with 12 hourly model snapshots at 0:00 and 12:00 of a model integration for the three months October to December 2007. The model was initialized on 19 September 2007 with a monthly mean climatology. Such a 12-hourly sampling well corresponds to the observed dynamics in the presence of tides. Nevertheless, this step already involves approximations. Indeed, here we replace the real initial model error statistics by variability of 
the prescribed model dynamics under variable atmospheric forcing. The degree of its closeness to the real set of probable uncertainties in initial states determines the quality of sampling and, thus, the time evolution of the statistics.

The first 8 EOFs of the model variability sampled by the noon and midnight snapshots have been used to generate an ensemble of initial model states (temperature, salinity, current velocities, sea surface elevation). The initial ensemble of 8 members spreads around the mean state and dynamically evolves in time. Such an approximation of model error covariances by an ensemble of a small size is quite crude, but works sufficiently well if the system is characterized by few strongly dominated dynamical modes (which is the case for the North Sea) and the filter analysis is performed under certain localization conditions. Results of an additional experiment with a bigger ensemble (16 members, not shown), under otherwise identical conditions, did not improve the agreement of the forecast with the SST observations and independent data.

\section{Observational errors}

The SST data used in this study have been provided without prior information on the error statistics $\rho_{d}(\mathbf{d} \mid \mathbf{x}(t))$. However, Høyer and She (2007), report a standard error of the SST satellite product $\left(\sigma_{s s t}\right)$ provided by the BSH of $\sim 0.7^{\circ} C$. This value can be used to partly account for $\rho_{d}(\mathbf{d} \mid \mathbf{x}(t))$. An additional source of the errors is due to the model representativeness. For instance, at the analysis and forecast steps, we compare the model state each 12 hours against satellite observations, which are cumulative over the 12 hours window. We stress, however, that $\sigma_{s s t}$ in the data assimilation algorithm 
is not just the standard deviation of the data errors, but - due to the link between model uncertainties and data errors relative to the reality — reflects and therefore determines the ratio between model and data quality, which we are not confident about. In other words, when the reality is unknown and is to be estimated based on available information (model and data), which quality is neither well known, the error statistics of the information sources are always conditional.

No information is available about the data error correlation. The correlation length scale, to some extent, depends on the dynamics of the basin, more precisely, on the Rossby radius of deformation, which varies from $\sim 200$ $\mathrm{km}$ in the barotropic mode to $\sim 10 \mathrm{~km}$ or even less in the baroclinic mode (Alenius et al., 2003; Fennel et al., 1991). In every particular location of the North and Baltic Seas, the SST data error correlation length scale might be determined by the energy superposition of the baroclinic and barotropic flows. The dependencies of the data error correlation on the system dynamics is brought about by the algorithm used to convert the signal detected by satellite sensors to the bulk temperature at $1 \mathrm{~m}$ depth. The algorithms are based on regression analysis relating the signal to in situ observations available just at a limited number of locations but spread over large areas with different local dynamics. Indirectly, the data errors depend on the system dynamics due to representativeness of the satellite data interpolated from the original resolution of $1.5 \mathrm{~km}$ to the coarser model grid.

Through the dependence on system dynamics, the data error correlation length scale could be linked to the localization radius. From the point of view of the local SEIK filter algorithm, the localisation radius should be small 
enough to allow the small ensemble to approximate, by different combinations of the members, the error covariance matrix in such a way that the matrix, being still of low rank locally for the subspace, on the whole, would describe the uncertainties in a higher dimensional space (Hunt et al., 2007; Nerger et al., 2006). On the other hand, the localisation radius should be large enough to account for a sufficient amount of sparse data.

In our study, the following assumptions on data error have been considered. We have tested $\sigma_{s s t}$ equal to $1.8^{\circ} \mathrm{C}, 0.8^{\circ} \mathrm{C}$ and $0.5^{\circ} \mathrm{C}$. To approximate the error correlation, we have weighted the data within the radius of $150 \mathrm{~km}$, $100 \mathrm{~km}$ and $50 \mathrm{~km}$ assuming exponential, quasi Gaussian (Gaspari and Cohn, 1999) or uniform dependence of the weights on the distance from the analysed grid point. We stress once again that values here do not pertain to quantitative estimates of the data error statistics, they rather express conditional data quality. It turned out that the choice of $\sigma_{s s t}=0.8{ }^{\circ} \mathrm{C}$ and the exponential form of data error correlation within $100 \mathrm{~km}$ (we refer to this setup as "main experiment") were the best among others tested. Below we only discuss the impact of our assumptions about data error statistics on the SST forecast and illustrate their influence on salinity simulations when comparing the main experiment against those with uniform data weighting within $50 \mathrm{~km}$.

\subsection{Different timing and period of LSEIK analyses and forecasts}

Developing an operational forecasting system including data assimilation, one has to address one more aspect of data product statistics such as frequency and spatial coverage of available information. To evaluate the system's forecasting skills in the presence of spatial and temporal satellite SST 
data gaps, four basic experiments, differing with respect to DA frequency and the forecast period, have been carried out:

1. 12 hours forecast when assimilating SST data at 0:00 and 12:00;

2. assimilation followed by long forecasts over 48 and 120 hours;

3. 12 and 24 hours forecast with LSEIK filter applied every 24 hours at 0:00

4. 12 and 24 hours forecast with LSEIK filter applied every 24 hours at 12:00.

Since the implemented data assimilation approach assumes a dynamically evolving forecast error covariance matrix, the system was initialized for all experiments with the same ensemble of states based on the covariances described above.

\section{Results}

4.1. Main experiment: improving the agreement of the analysis/forecast with the observations

Figures 1 and 2 demonstrate the improvement of the BSH system SST forecasting skill on 14 and 27 October 2007 respectively when assimilating the SST data every 12 hours. The top left panels depict the absolute deviation of SST model solution from satellite data when no DA is applied. The top left panel of Figure 1 shows that the model has difficulties in reproducing the observed SST in the interior region of the Baltic Sea, over the area of the Inner Silver Pit and in the English Chanel, while the ensemble mean of model temperature updated after the local SEIK filter analysis much better 
agrees with the satellite-derived data (bottom left panel of Figure 1). This reinitialization of the system at the analysis step has allowed us to reduce the deviation of the SST ensemble mean forecast from the observations (top right panel). The bottom right panels of Figures 1 and 2 show the differences between the respective top right and left panels, which characterises the improvement of forecast. Apparently, with SST observational data assimilation, we reduce the deviation of model 12 hours forecast from the satellite data by more than $1^{\circ} \mathrm{C}$. Figure 2 also illustrates how sparse the satellite data sometimes are.

Figure 3 compares the temporal evolution of root mean square (RMS) estimates of the SST forecast-data deviation over October 2007 obtained by the BSH circulation model with and without data assimilation and averaged over the full model domain. The black curve represents the RMS estimates without assimilation, while the blue curve and the dots are those obtained with the local SEIK filter applied every 12 hours. With data assimilation, the deviation of the forecasted SST from the satellite measurements is significantly, $\sim 27 \%$, reduced and approaching to $0.5^{\circ} C$. Looking at the differences between the forecast and analysis (the dashed red curves) one can get an impression about the real forecast quality or, in other words, model uncertainties which have also reduced in comparison with BSHcmod without DA.

\subsection{Influence of data errors and localization radius}

The results presented above pertain to the main experiment. As compared, for instance, with the case of uniform data weights over the radius of $50 \mathrm{~km}$, the SST forecast in the main experiment is improved by a max- 
imum $10 \%$ (Fig. 4). Very similar SST forecast quality to that of the main experiment has been obtained with the LSEIK filter using the quasi-Gaussian data error correlation function (Gaspari and Cohn, 1999) within $50 \mathrm{~km}$ and $\sigma_{s s t}=0.8^{\circ} \mathrm{C}$ (not shown). However, the degree of closeness of the predicted SST to those observed was not the only criterion of the BSH service improvement we considered. The sea surface height, current velocities and salinity simulations were also under the control. The sea surface elevation of LSEIK analysis and forecast were always sufficiently close to the BSH forecast without DA, which, on its own, is in a good agreement with tide gauge data (Dick et al., 2001). The maximum differences between the SSH forecast with and without SST data assimilation are less than $2 \mathrm{~cm}$. Deviations of the velocity components ( $u$ and $v$ ) obtained with regular BSHcmod from those in the DA setup based on local SEIK filtering under conditions of the main experiment were also quite small $(\sim 1.5 \mathrm{~cm} / \mathrm{s}$ maximum), at least over the considered time period. Using other localisation parameters mentioned in Section 3 including the quasi-Gaussian correlation function - at the analysis step, however, led to $u$ and $v$ with a higher noise component (not shown).

\section{Comparison with independent data}

Faithful modelling of salinity presents a really tough criterion for the forecasting system performance as the horizontal and vertical salinity distribution is a key factor determining the Baltic See stratification, ventilation processes and important environmental conditions for a unique marine ecosystem. It turned out that salinity is rather sensitive to the configuration details of the LSEIK filter algorithm.

Figure 5 shows that the assumption on data error statistics in the main 
experiment is superior for the salinity simulation (red curve). The surface and bottom salinity at the MARNET station Arkona Basin in the Baltic Sea (located at $54^{\circ} 53^{\prime} N, 13^{\circ} 52^{\prime} E$ ) obtained by assimilating the SST data in the main experiment is compared with simulations performed without DA (blue curve) and with DA (black dashed) using a $50 \mathrm{~km}$ radius of data influence, $\sigma_{s s t}=1.8^{\circ} \mathrm{C}$ and uniform data weights. Independent time series data at the MARNET station are given by the green curve. One can see that the forecast quality for salinity crucially depends on the assumptions about the model and data error statistics. We have to, however, mention that it is rather difficult to correctly reproduce the system dynamics in the location of the MARNET stations. In the presence of realistic bathymetry, the dynamics are characterized by very strong and sporadic interactions between the North and Baltic Seas, which the used version of the BSH circulation model with the $5 \mathrm{~km}$ resolution does not always properly predict.

Table 1 summarises the statistics of the surface salinity forecast deviation from independent observations at a number of MARNET stations. At the two stations Darss Sill and Fehmarn Belt, the SST data assimilation just slightly improved the salinity forecast. The predicted SST based on LSEIK analysis is, however, in a very good agreement with all the MARNET SST observations (see Tab. 2). At the MARNET locations, the deviation of the predicted SST from the independent time series is much less in case with DA than without it and even less than the differences between the satellite SST and the MARNET data. 


\subsection{Bias reduction and long forecasts in the presence of data gaps}

Figure 6 illustrates the ability of the DA system to correct systematic model errors. It depicts spatial distribution of deviation of the sea surface temperature forecast from the satellite data obtained without DA (top panel) and with 12-hourly implemented local SEIK filter (bottom panel) averaged over the period October 2007. As shown in the top panel, over the period considered, the BSH circulation model underestimates surface temperature in the Skagerrak and Kattegat straits, in the Darss Sill and the Arkona Basin. Larger deviations are also visible in the Norwegian Trench and the Gulf of Bothnia. In the English Chanel, over the area of the Inner Silver Pit and in the interior region of the Baltic Sea, the predicted surface temperature is more than $1^{\circ} \mathrm{C}$ less than the observed one. The model state corrections we have obtained after the local SEIK analysis step were sufficient to keep the model trajectories in the right direction and, therefore, to improve the forecast over 12 hours (Fig. 6, bottom panel). Averaged over the basin mean deviation of the model SST from the NOAA observations decreased from $0.56^{\circ} \mathrm{C}$ to $0.20^{\circ} \mathrm{C}$ when local SEIK filtering was applied.

An important question is how long the model is able to keep the right course. Figure 7 depicts the temporal evolution of RMS estimates (RMSE) of the differences between SST data and a 5-day forecast initialized by the LSEIK analysis on 16 October 2007 (green curve). The estimates are compared with those obtained for the forecast without DA (black curve) and the ensemble mean forecast with 12-hourly DA (blue curves/dots). It is worth noting that, over the entire period of 120 hours, the quality of the model forecast based on LSEIK update just at the beginning of the integration period 
is better than regular the BSHcmod SST forecast performed without any DA, and close - especially over the first 48 hours - to the forecast quality of the system with DA every 12 hours. Similar results have been obtained when carrying out a real-time data assimilation experiment over March 2011: 48-hour forecasts initialized after the LSEIK analysis on 23 March 2011, 25 March 2011 and 27 March 2011 turned out to be of the same quality as the forecast based on DA every 12 hours (Fig. 8). Overall, the reduction of the RMS error of SST forecasts achieved during the real-time data assimilation experiment is from $0.87^{\circ} \mathrm{C}$ to $0.53^{\circ} \mathrm{C}$ (Fig. 9).

\subsection{Filtering with different timing and frequency: bias of the daytime satel- lite data product}

Figure 10 displays RMS forecast-minus-data estimates of DA experiments with different timings. In particular, we compare the RMSE of the deviation of SST forecast from the observations obtained with DA every 24 hours at 12:00 (blue curve) against the case of only 'midnight' data assimilation (every 24 hours at 0:00, green curve) and every 12 hours LSEIK filtering (red curve). The black curve is again the SST forecast-minus-data RMSE temporal evolution for the BSHcmod without DA. The red and green curves indicate that adding the daytime data to midnight data does not bring any significant information into the forecasting system with respect to improving the forecast quality. Moreover, the blue curve shows that assimilation of only daytime SST can make the forecast even worse. Indeed, this result is an illustration of AVHRR-derived daytime data bias due to spatial thermostratification of the upper few millimeters ocean/sea layer forming during daytime under lowwind speed conditions (Donlon et al., 2002). The existence of such a diurnal 
warm layer makes the relation of sea surface skin temperature, measured by the sensors, to the subsurface $1 \mathrm{~m}$ depth temperature quite complicated. In our case, the amplitude of the satellite-derived temperature daily cycle is up to $3.5^{\circ} \mathrm{C}$. Several methods of removing the effect of diurnal warming have been proposed based on wind and surface heat-flux data (Gentemann et al., 2003; Stuart-Menteth et al., 2004; Nardelli et al., 2004). However, seemingly, there is no well established parameterization of the "skin effect" for the North and Baltic Seas. We see the results of Figure 10 as remarkable illustration of the capability of a calibrated DA system to pick up a relevant part of information from otherwise noisy data.

\section{Summary and Conclusions}

A data assimilation (DA) system based on a variety of localized ensemble Kalman filter has been coupled to the operational BSH circulation model of the North and Baltic Seas. The method was successfully applied for assimilation of NOAA's satellite sea surface temperature data. We demonstrate that, over the period of October 2007, the agreement of the SST forecast with the satellite observation has been improved by $\sim 27 \%$ in comparison with the regular BSH forecast without DA. To a large extent, this improvement has been achieved by implementing the ensemble based filter locally under assumption of an observation error of $0.8^{\circ} \mathrm{C}$ and using an exponential function to approximate the data error correlation within the $100 \mathrm{~km}$ radius and with ensemble size of 8 members. The system's forecasting skills are sensitive to the assumptions on data error statistics. The statistics is, nevertheless, conditional as is related to the reality which is, indeed, unknown and 
is estimated based on the model and data. Adjustment of the radius of data influence as well as the data error correlation function has been required to obtain better agreements of the salinity prediction in the Arkona basin with independent data. Further tuning of the data assimilation system could be done by introducing a spatially variable localisation radius, that would correspond to the data error correlation length scale. This is in agreement with Høyer and She (2007) who noted the dependence of the SST error correlation length scale on the bathymetry and dynamics of the basin.

The major improvements in the SST forecast have been achieved due to the fact that, after the filter analysis and update, the model states possessed much less systematic errors in comparison with model solution obtained without DA. The system dynamics kept the memory about the corrections and drove the model trajectories in the "right" direction over up to 120 hours, which is valuable in the presence of SST satellite data gaps and also provides an opportunity for improving up to 5 days-long forecasts.

We have also reported on a real-time data assimilation experiment carried out in March 2011. Over this period, the assimilation of the AVHRR-derived SST data every 12 hours allowed the BSH system to reduce the deviation of the SST forecast in the North and Baltic Seas from observations by $\sim 39 \%$. On average, RMS estimates of the differences have been reduced from $0.87^{\circ} \mathrm{C}$ to $0.53^{\circ} \mathrm{C}$. It is worth mentioning that the forecast's quality with respect to the observation remained good during up to 48 hours after the DA analysis.

Results of data assimilation with different timing and frequency reveal low informative influence of daytime AVHRR data when assimilating the satellite SST (including midnight data) every 12 hours, but highlight the problem of 
filter performance if only the 12 hours composites around 12:00 are used. This can be considered as an apparent illustration of the fact that the AVHRR daytime product for the North and Baltic Seas does not properly account for skin temperature effects. To this end, it is worth noting that despite the high sensitivity of the forecast quality improvement to assumptions about model uncertainties and data errors, statistics of which are not always, if ever, known a priori, the combination of the information from the model and the data by data assimilation might itself improve our understanding of both these sources and help to optimize the system.

The potential for further optimisation and extension of the operational BSH system by assimilating additional data sets — such as radar data, MARNET time series, sea ice thickness and concentration - open attractive perspectives for future research, including the North and Baltic Seas hydrographic state reanalysis.

\section{Acknowledgments}

The authors are grateful to Tijana Janjić for valuable discussions on localization; to NOAA and BSH SST satellite data service for providing the data. Comments and support by the editor and anonymous reviewers were very helpful. The work was supported within project DeMarine-Environment by the German Federal Ministry of Economics and Technology(BMWi) through the German Aerospace Center(DLR).

\section{References}

Alenius, P., Nekrasov, A., Myrberg, K., 2003. Variability of the baroclinic Rossby radius in the Gulf of Finland. Continental Shelf Research 23, 563- 
573.

Bertino, L., Lisæter, K. A., 2008. The TOPAZ monitoring and prediction system for the Atlantic and Arctic Oceans. Journal of operational oceanography $1(2), 15-18$.

Bishop, C. H., Etherton, B., Majumdar, S., 2001. Adaptive sampling with the ensemble transform Kalman filter. Part I: Theoretical aspects. Mon. Wea.Rev. 129, 420-43.

Brasseur, P., Bahurel, P., Bertino, L., Birol, F., Brankart, J. M., Ferry, N., Losa, S., Remy, E., Schröter, J., Skachko, S., Testut, C. E., Tranchant, B., van Leeuwen, P. J., Verron, J., 2005. Data assimilation for marine monitoring and prediction: the MERCATOR operational assimilation systems and the MERSEA developments. Quarterly Journal of the Royal Meteorological Society 131(613), 3561-3582.

Brusdal, K., Brankart, J. M., Halberstadt, G., Evensen, G., Brasseur, P., van Leeuwen, P. J., Dombrowsky, E., Verron, J., 2003. A demonstration of ensemble based assimilation methods with a layered OGCM from the perspective of operational ocean forecasting systems. Journal of Marine Systems 40-41, 253-289.

Cummings, J., Bertino, L., Brasseur, P., Fukumori, I., Kamachi, M., Martin, M., Mogensen, K., Oke, P., Testut, C., Verron, J., Weaver, A., 2009. Ocean Data Assimilation Systems for GODAE. Oceanography 22(3), 96-109.

Dick, S., 1997. Operationelles Modellsystem für Nord- und Ostsee. In: 
FORUM, Proc. Der Fachtagung 'EDV im Seeverkehr und maritimen Umweltschutz'. Bremen, pp. 22-25.

Dick, S., Kleine, E., Müller-Navarra, S. H., Klein, H., Komo, H., 2001. The operational circulation model of BSH (BSHcmod) model description and validation. Berichte des BSH.

Donlon, C. J., Minnett, P., Gentemann, C., Nightingale, T. J., Barton, I. J., Ward, B., Murray, J., 2002. Towards improved validation of satellite sea surface skin temperature measurements for climate research. J. Climate 15(4), 353-369.

Evensen, G., 1994. Sequential data assimilation with a non-linear quasigeostrophic model using Monte-Carlo methods to forecast error statistics. J. Geophys. Res. 99, 10143-10162.

Fennel, W., Seifert, T., Kayser, B., 1991. Rossby radii and phase speeds in the Baltic Sea. Continental Shelf Research 11, 23-26.

Gaspari, G., Cohn, S. E., 1999. Construction of correlation functions in two and three dimensions. Quart. J. Roy. Meteor. Soc. 125, 723-757.

Gentemann, C., Donlon, C., Stuart-Menteth, A., Wentz, F., 2003. Diurnal signals in satellite sea surface temperature measurements. Geophys. Res. Lett. 30(3), 1140-1143.

Ghil, M., Malonotte-Rizzoli, P., 1991. Data assimilation in meteorology and oceanography. Adv. Geophys. 33, 141-266. 
Gordon, N. J., Salmond, D. J., Smith, A. F. M., 1993. Novel approach to nonlinear/non-Gaussian Bayesian state estimation. IEE Proceedings F 140(2), 107-113.

Hibler, W. D., 1979. A dynamic/thermodynamic sea ice model. Journal of Physical Oceanography 9, 815-846.

Høyer, J. L., She, J., 2007. Optimal interpolation of sea surface temperature for the North Sea and Baltic Sea. J. Mar. Sys. 65, 1-4, 176-189.

Hunt, B. R., Kostelich, E. J., Szunyogh, I., 2007. Efficient data assimilation for spatiotemporal chaos: a local ensemble transform Kalman filter. Physica D 230, 112-126.

Janjić, T., Nerger, L., Albertella, A., Schröter, J., Skachko, S., 2011. On domain localization in ensemble based Kalman filter algorithms. Monthly Weather Review 136 (7), 2046-2060.

Jazwinski, A., 1970. Stochastic processes and filtering theory. Academic Press, New York.

Kivman, G. A., 2003. Sequential parameter estimation for stochastic systems. Nonlinear Processes in Geophysics 10 (3), 253-259.

Kleine, E., 1994. Das operationalle Modell des BSH für Nord- und Ostsee:Konzeption und Ubersicht. Berichte des BSH, Bremen.

Kleine, E., 2003. A class of hybrid vertical co-ordinates for ocean circulation modelling. In: Proceedings of the 6th HIROMB Scientific Workshop. St. Petersburg, pp. 7-15, [ISBN 5- 86813-132-0]. 
Kurapov, A. L., Foley, D., Strub, P. T., Egbert, G. D., Allen, J. S., 2011. Variational assimilation of satellite observations in a coastal ocean model off Oregon. J. Geophys. Res. 116, 1-19.

Larsen, J., Høyer, J., She, J., 2007. Validation of a hybrid optimal interpolation and kalman filter scheme for sea surface temperature assimilation. Journal of Marine Systems 65 (1-4), 122-133.

Miyoshi, T., Yamane, S., 2007. Local ensemble transform Kalman filtering with an AGCM at a T159/L48 resolution. Mon. Wea. Rev. 135, 3841-3861.

Nardelli, B. B., Marullo, S., Santoleri, R., 2004. Diurnal variations in AVHRR SST fields: A strategy for removing warm layer effects from daily images. Remote Sensing of Environment 95(1), 47-56.

Nerger, L., Danilov, S., Hiller, W., Schröter, J., 2006. Using sea level data to constrain a finite-element primitive-equation model with a local SEIK filter. Ocean Dynamics 56, 634-649.

Nerger, L., Hiller, W., 2012. Software for Ensemble-based Data Assimilation Systems - Implementation Strategies and Scalability. Computers and Geosciences(In press.).

Nerger, L., Hiller, W., Schröter, J., 2005. PDAF - The Parallel Data Assimilation Framework: Experiences with Kalman Filtering. In: Zwieflhofer, W., Mozdzynski, G. (Eds.), Use of high performance computing in meteorology: proceedings of the Eleventh ECMWF Workshop on the Use of High Performance Computing in Meteorology. Singapore: World Scientific, Reading, UK, 25 - 29 October 2004, pp. 63-83. 
Penduff, T., Brasseur, P., Testut, C.-E., Barnier, B., Verron, J., 2002. A four-year eddy-permitting assimilation of sea-surface temperature and altimetric data in the South Atlantic Ocean. Journal of Marine Research $60(6), 805-833$.

Pham, D. T., 2001. Stochastic methods for sequential data assimilation in strongly nonlinear systems. Mon. Weather Rev. 129, 1194-1207.

Pham, D. T., Verron, J., Gourdeau, L., 1998. Singular evolutive Kalman filters for data assimilation in oceanography. C. R. Acad. Sci. Paris, Earth and Planetary Sciences 326, 255-260.

Ryder, P., 2007. GMES fast track marine core service: Strategic implementation plan.

She, J., Jacob, L., Høyer, J. L., Larsen, J., 2007. Assessment of sea surface temperature observational networks in the Baltic Sea and North Sea. J. Mar. Sys. 65, 314-335.

Stanev, E. V., Schulz-Stellenfleth, J., Staneva, J., Grayek, S., Seemann, J., Petersen, W., 2011. Coastal observing and forecasting system for the German Bight - estimates of hydrophysical states. Ocean Sci. 7, 569-583.

Storkey, D., Blockley, E. W., Furner, R., Guiavarc'h, C., Lea, D., Martin, M. J., Barciela, R. M., Hines, A., Hyder, P., Siddorn, J. R., 2010. Forrecasting the ocean state using NEMO: The new FOAM system. Journal of operational oceanography $3(1), 11-15$.

Stuart-Menteth, A. C., Robinson, I. S., Donlon, C. J., 2004. Sensitivity of 
the diurnal warm layer to meteorological fluctuations Part 2: a new parameterisation for diurnal warming. Journal of Atmospheric and Ocean Science.

Testut, C.-E., Brasseur, P., Brankart, J.-M., Verron, J., 2003. Assimilation of sea-surface temperature and altimetric observations during 19921993 into an eddy permitting primitive equation model of the north atlantic ocean. Journal of Marine Systems 40-41, 291-316.

van Leeuwen, P. J., 2009. Particle filtering in geophysical systems. Monthly Weather Review 137(12), 4089-4098.

van Leeuwen, P. J., 2010. Nonlinear data assimilation in geosciences: an extremely efficient particle filter. Quart. J. Roy. Meteor. Soc. 136.

van Leeuwen, P. J., Evensen, G., 1996. Data assimilation and inverse methods in terms of probabilistic formulation. Month. Weath. Rev. 124, 2898-2913. 

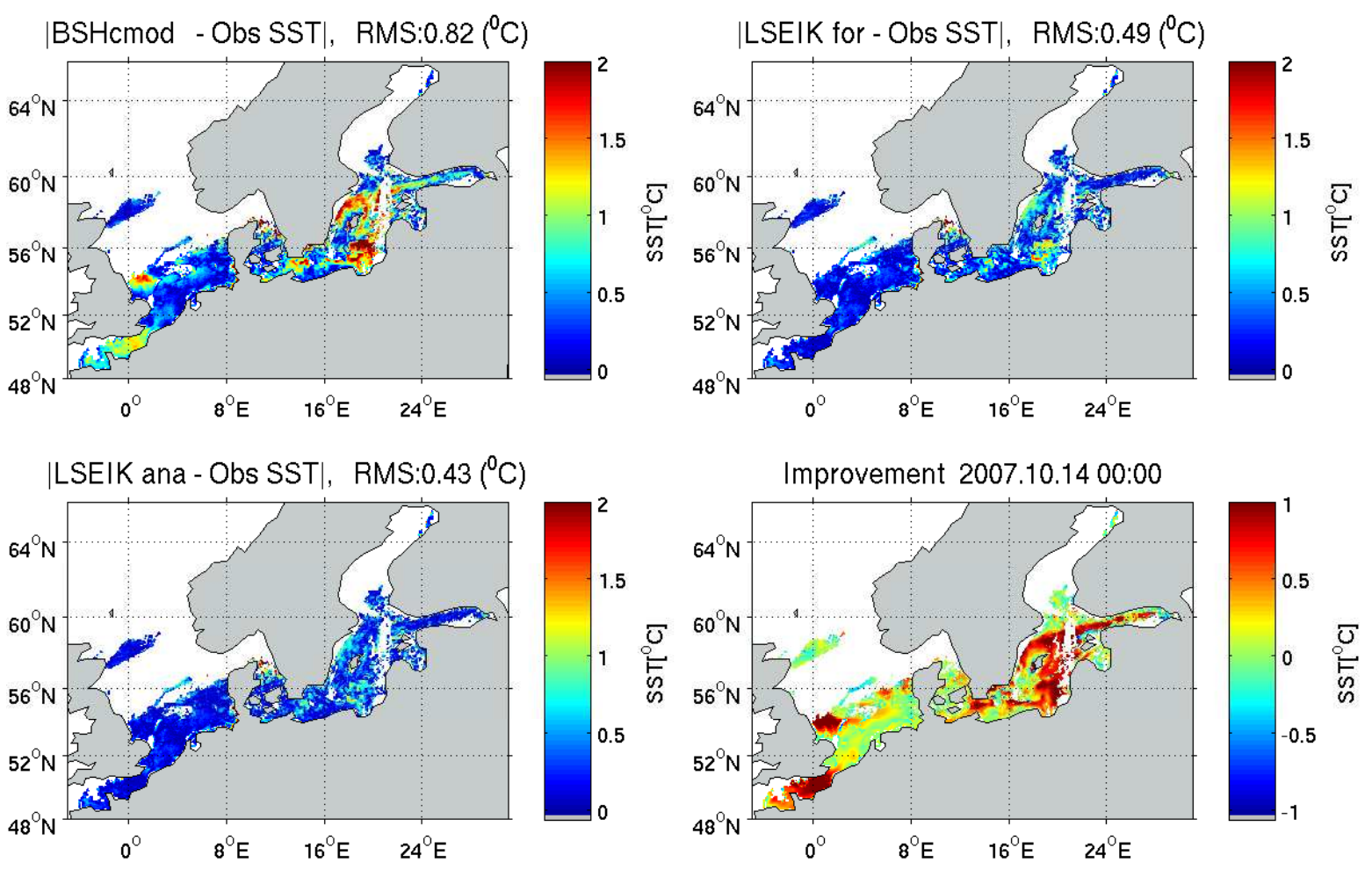

Figure 1: SST forecast skill improvement on 14 October 2007 at 00:00: Absolute deviation from NOAA SST data of BSHcmod forecast without DA (top left), LSEIK 12-hour forecast (top right), analysis (bottom left) and improvement as difference of the absolute deviations without and with DA (bottom right). 

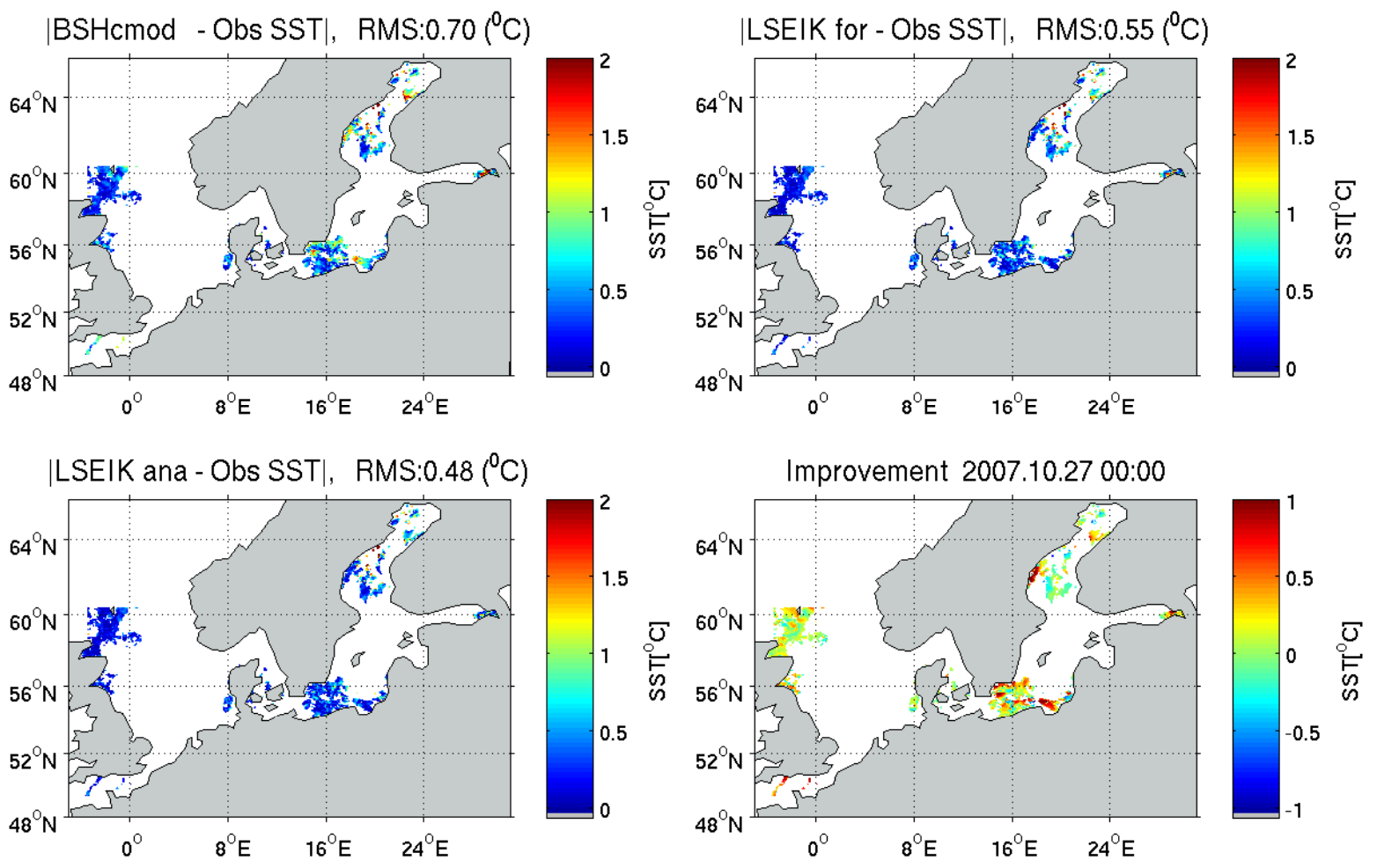

Figure 2: SST forecast skill improvement on 27 October 2007 at 00:00: Absolute deviation from NOAA SST data of BSHcmod forecast without DA (top left), LSEIK 12-hour forecast (top right), analysis (bottom left) and improvement as difference of the absolute deviations without and with DA (bottom right). 


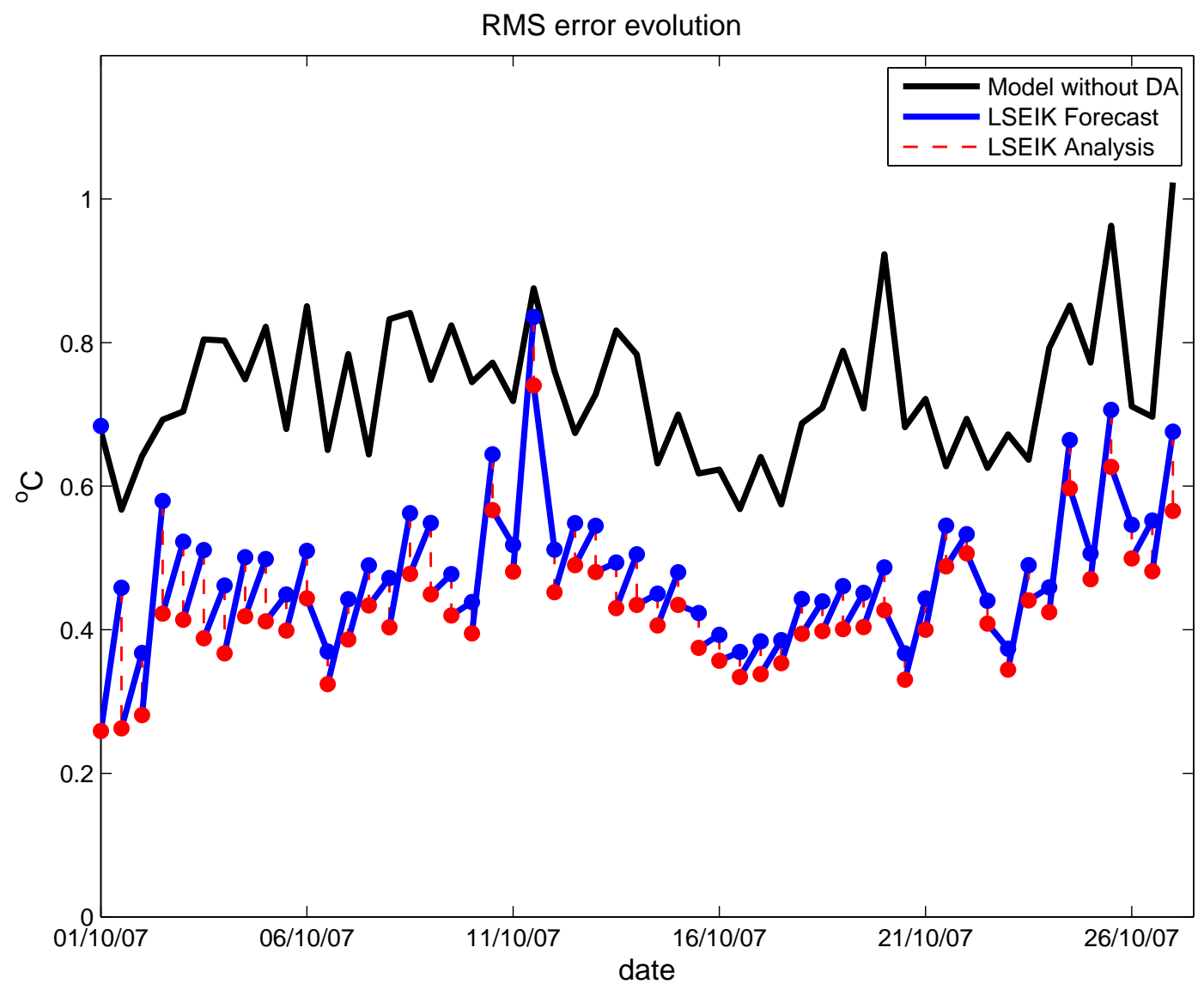

Figure 3: Temporal evolution of RMS differences between satellite SST data and BSHcmod forecast (black), LSEIK analysis (red) and mean of ensemble forecast (blue) based on 12hourly LSEIK analysis over the period 1 October 2007 - 27 October 2007. 


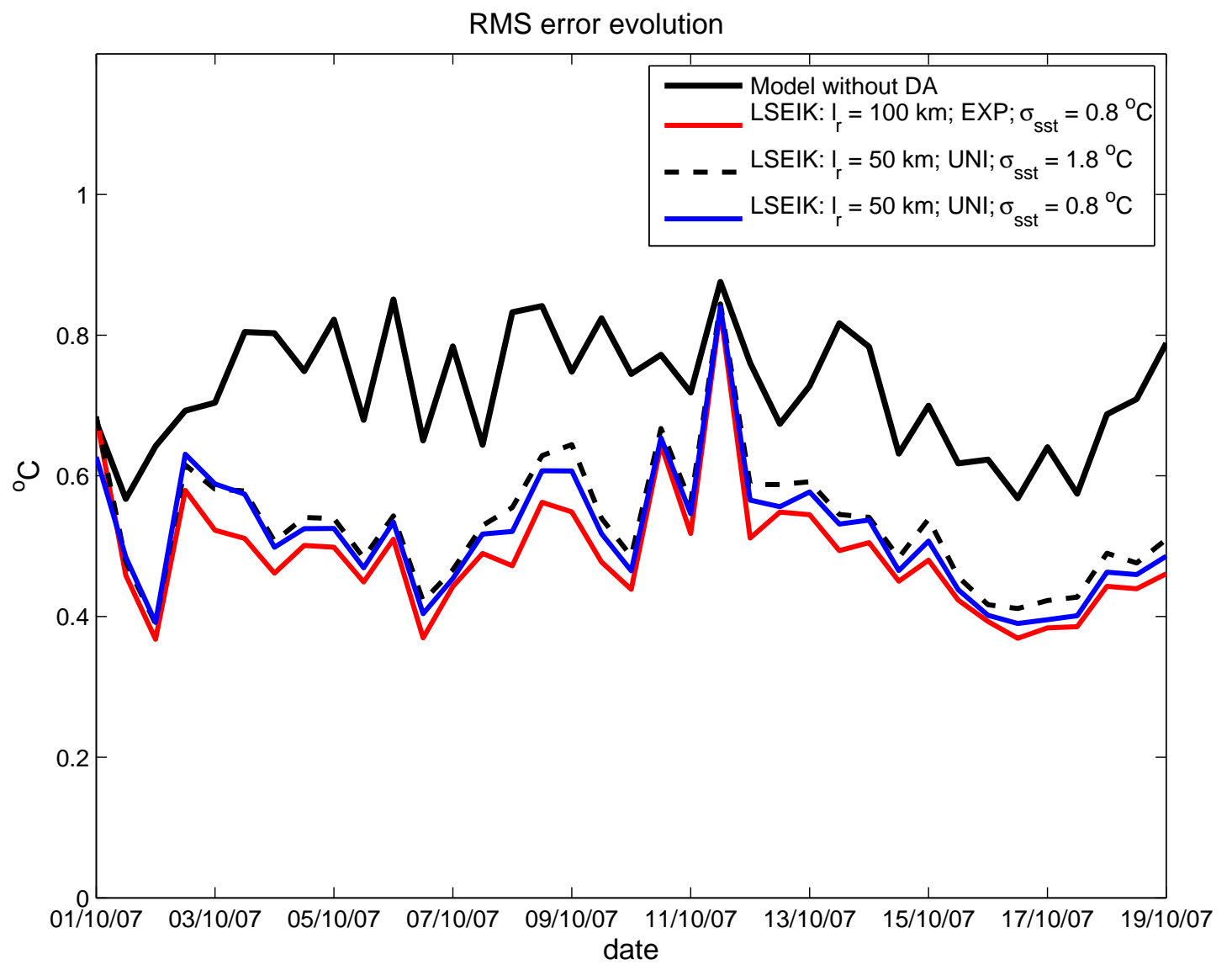

Figure 4: Temporal evolution of RMS deviation of SST model forecast from satellite SST data over the period 1 October 2007 - 19 October 2007: Forecast without data assimilation (black solid); mean of ensemble forecasts based on 12-hourly LSEIK analysis with uniform data weighting within $50 \mathrm{~km}$ and $\sigma_{s s t}=1.8^{\circ} \mathrm{C}$ (black dashed), with uniform data weighting within $50 \mathrm{~km}$ and $\sigma_{\text {sst }}$ of $0.8^{\circ} \mathrm{C}$ (blue) and with exponential data weighting within $100 \mathrm{~km}$ and $\sigma_{s s t}$ of $0.8^{\circ} \mathrm{C}$ (red). 

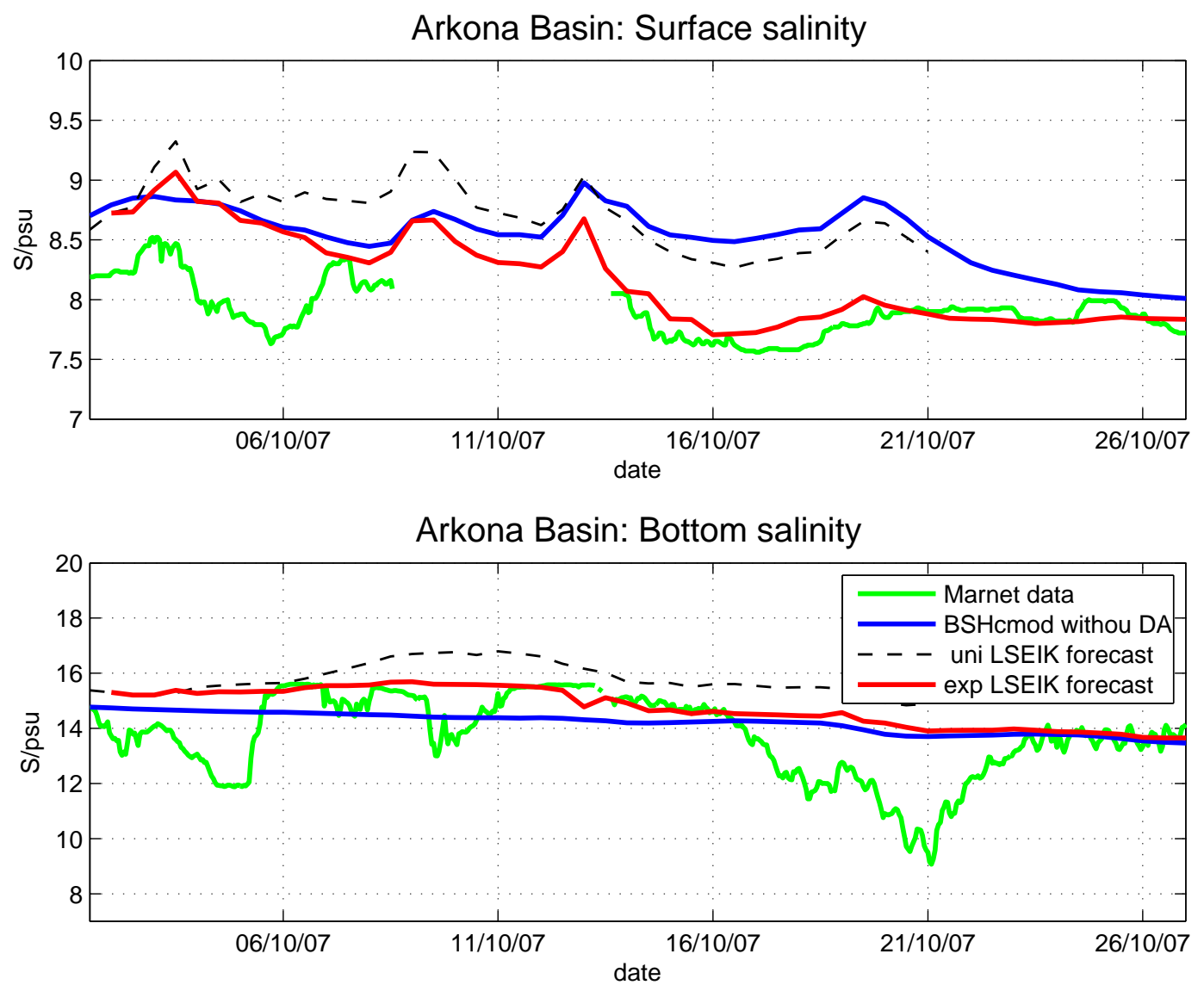

Figure 5: Surface (top panel) and bottom (bottom panel) salinity at the MARNET station "Arkona Basin": observation (green), model solution without DA (blue), forecast based on local SEIK analysis with uniform data weighting (black) and LSEIK forecast with exponential data weighting (red). 

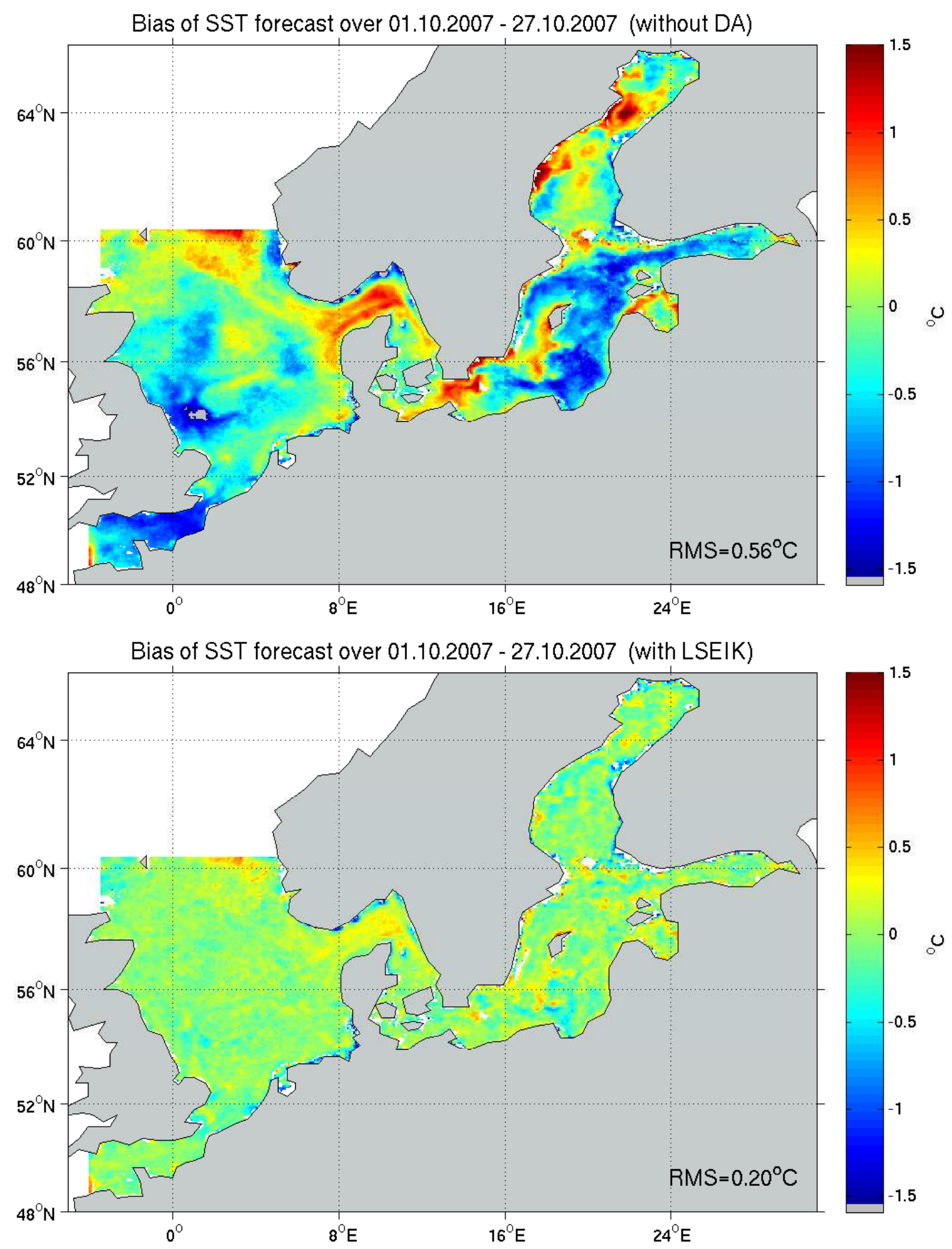

Figure 6: Mean deviation of the SST forecast from the satellite observations averaged over the period 1 October 2007 - 27 October 2007: Without DA (top) and with LSEIK filter (bottom). 


\section{RMS error evolution}

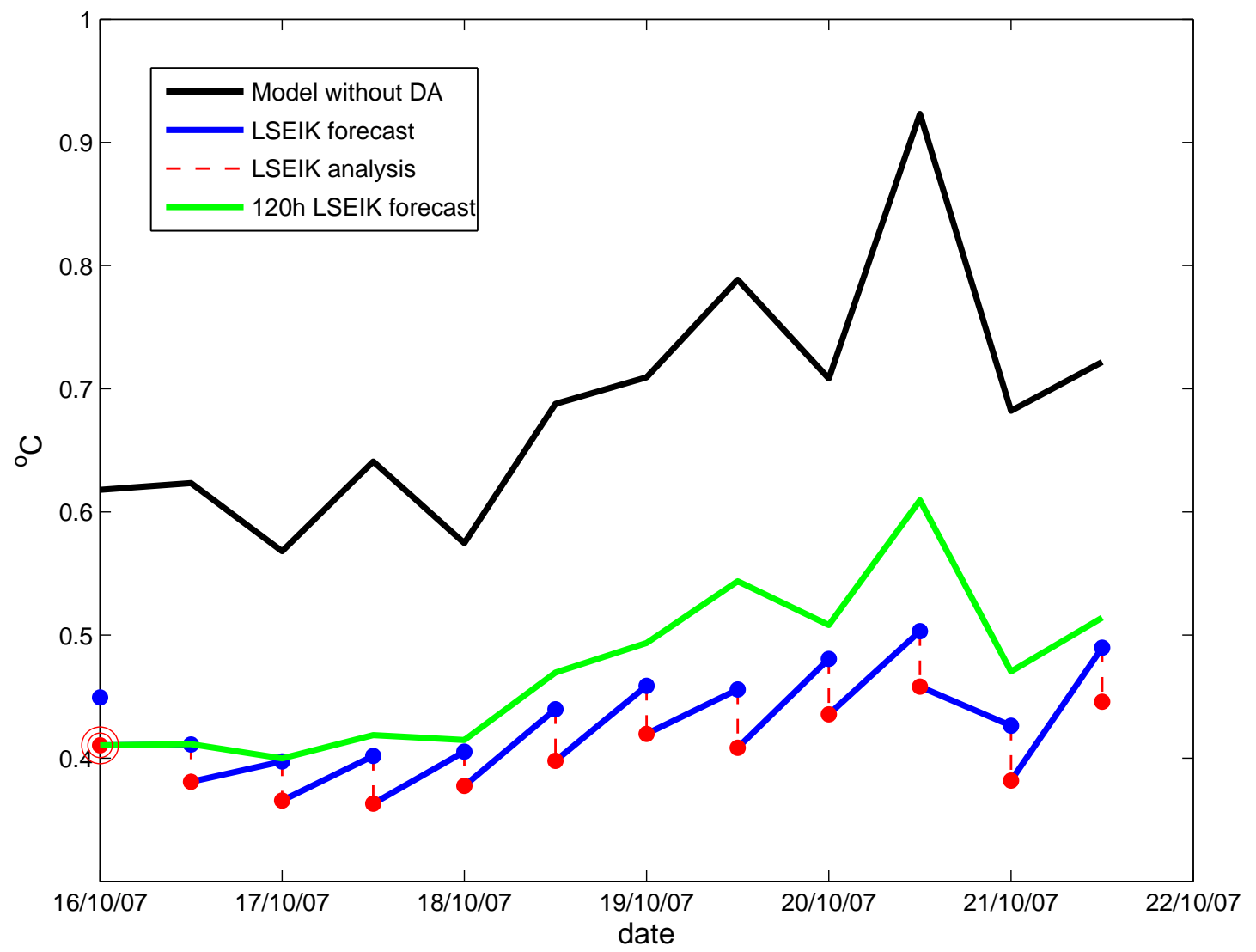

Figure 7: RMS error temporal evolution over the period 16 October 2007 - 21 October 2007 for simulated SST without DA (black curve); LSEIK analysis (red); mean of ensemble forecast based on 12-hourly analysis (blue) and 5 days forecast (green curve) initialized with the analysis state obtained on 16 October 2007. 
RMS error evolution

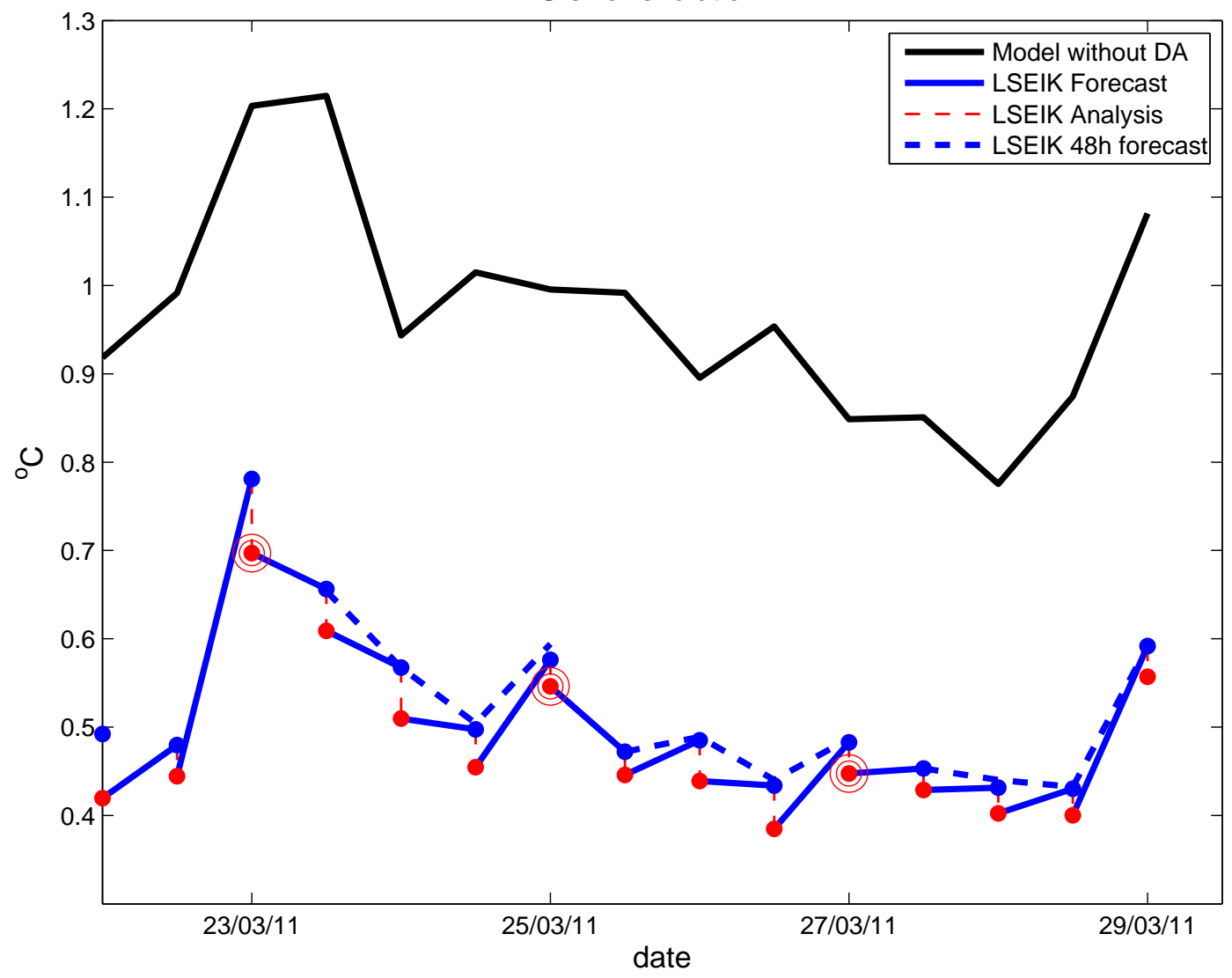

Figure 8: RMS error temporal evolution over the period 22 March 2011 - 29 March 2011 for simulated SST without DA (black curve); LSEIK analysis (red); mean of ensemble forecast based on 12-hourly analysis (blue) and 2-day forecasts (blue dashed curve) initialized with the analysis on 23 March 2011, 25 March 2011 and 26 March 2011. 


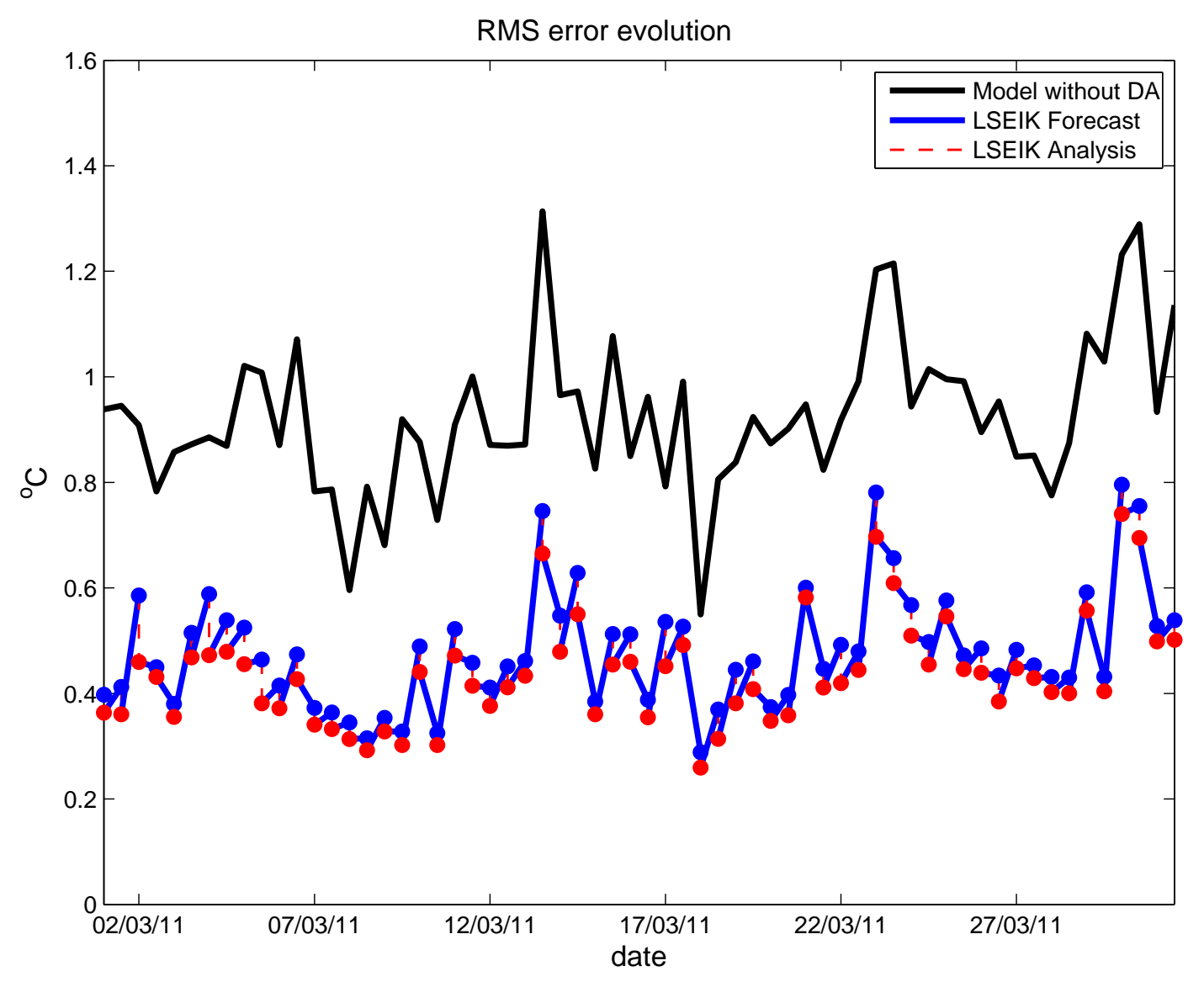

Figure 9: Temporal evolution of RMS differences between satellite SST data and BSHcmod forecast (black), local SEIK analysis (red) and SST ensemble mean forecast (blue) based on 12-hourly LSEIK analysis over the period 1 March 2011 - 31 March 2011. 
RMS error evolution

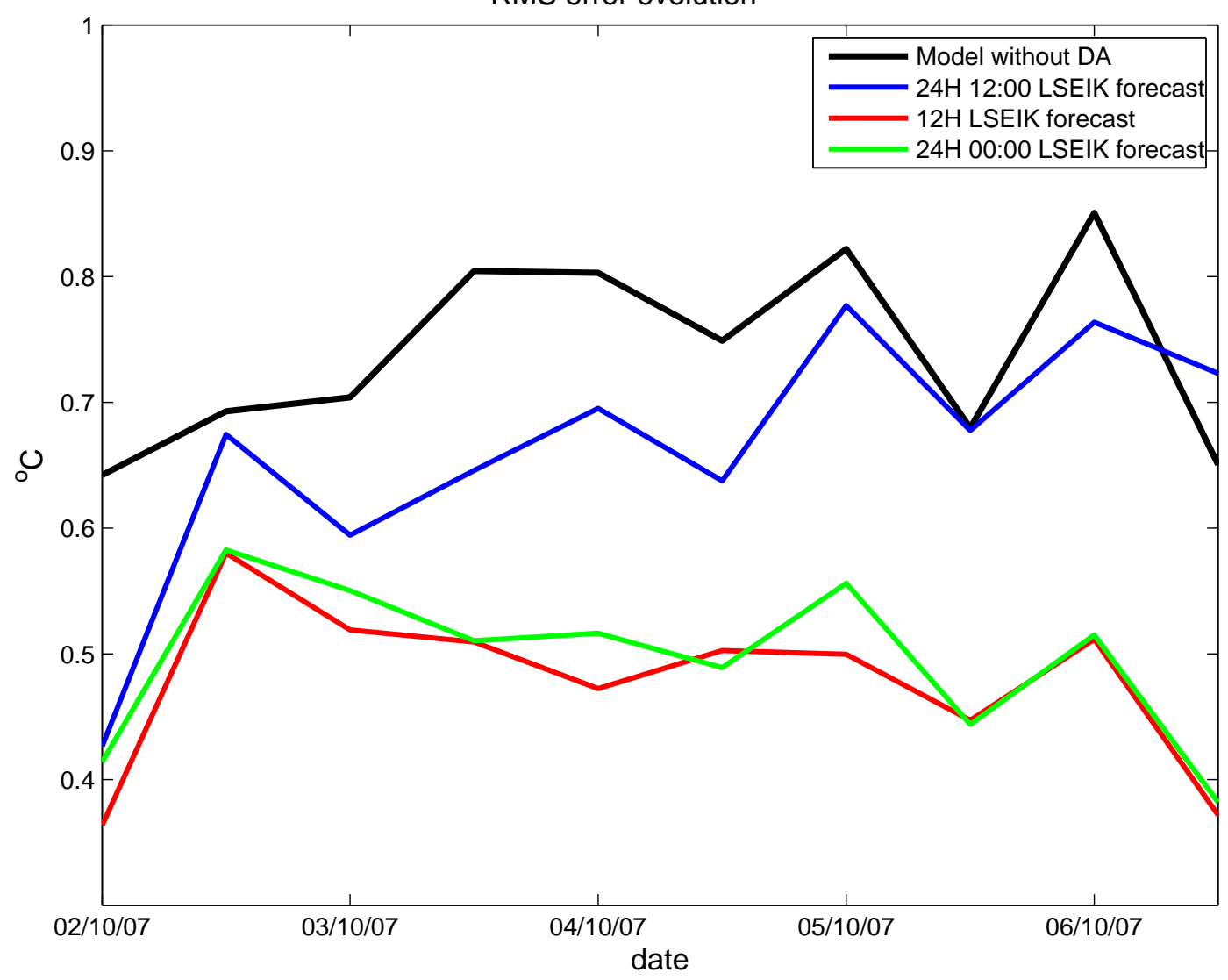

Figure 10: Temporal evolution of SST RMS error for BSHcmod forecast without DA (black); LSEIK forecast with DA every 12 hours at 0:00 and 12:00 (red); LSEIK forecast with the analysis every 24 hours at 0:00 (green); LSEIK forecast when assimilating the data every 24 hours at 12:00 (blue). 
Table 1: Deviation of the sea surface salinity predicted with and without DA from the MARNET observations over the period of October 2007.

\begin{tabular}{|c|c|c|c|c|c|}
\hline & & $R M S$ & $(p s u)$ & Mean & $(p s u)$ \\
\hline Station & Location & BSHcmod & $L S E I K$ & BSHcmod & $L S E I K$ \\
\hline Arkona & $54^{\circ} 53^{\prime} N, 13^{\circ} 52^{\prime} E$ & 0.61 & 0.36 & 0.53 & 0.26 \\
\hline Darss & $54^{\circ} 42^{\prime} N, 12^{\circ} 42^{\prime} E$ & 4.86 & 4.63 & 4.59 & 4.32 \\
\hline Oder & $54^{\circ} 05^{\prime} N, 14^{\circ} 10^{\prime} E$ & 0.59 & 0.50 & 0.48 & 0.39 \\
\hline Fehmarn & $54^{\circ} 36^{\prime} N, 11^{\circ} 09^{\prime} E$ & 5.82 & 5.82 & 5.73 & 5.71 \\
\hline$n s b$ & $55^{\circ} 00^{\prime} N, 06^{\circ} 20^{\prime} E$ & 0.13 & 0.12 & -0.09 & -0.07 \\
\hline Germ. Bight & $54^{\circ} 10^{\prime} N, 07^{\circ} 27^{\prime} E$ & - & - & - & - \\
\hline
\end{tabular}

Table 2: Deviation of the SST predicted with and without DA and AVHRR-derived temperature from the MARNET observations over the period of October 2007.

\begin{tabular}{l|ccc|ccc}
\hline \hline & \multicolumn{3}{|c|}{$\operatorname{RMS}\left({ }^{\circ} \mathrm{C}\right)$} & \multicolumn{3}{c}{ Mean $\left({ }^{\circ} \mathrm{C}\right)$} \\
\hline Station & BSHcmod & LSEIK & NOAA & BSHcmod & LSEIK & NOAA \\
\hline Arkona & 0.80 & 0.33 & 0.42 & 0.69 & 0.09 & 0.11 \\
Darss & 0.67 & 0.35 & 0.45 & 0.39 & 0.02 & 0.05 \\
Oder & 0.27 & 0.20 & 0.46 & 0.22 & 0.13 & 0.09 \\
Fehmarn & 0.26 & 0.22 & 0.40 & 0.06 & 0.06 & 0.01 \\
Germ. Bight & 0.39 & 0.33 & 0.36 & 0.23 & 0.13 & 0.05 \\
\hline
\end{tabular}

